\title{
BUCKLING ANALYSIS OF CARBON EPOXY TRAILING EDGE WING RIB
}

\author{
YELLURI SHWETHA ${ }^{1}$, GELLA SHIVA DURGA MADHAV ${ }^{2} \&$ DUSSA GOVARDHAN $^{3}$ \\ ${ }^{1,2}$ Assistant Professor, Institute of Aeronautical Engineering, Dundigal, Hyderabad, India \\ ${ }^{3}$ Professor, Institute of Aeronautical Engineering, Dundigal, Hyderabad, India
}

ABSTRACT
For Aerodynamic reasons, the chord wise of wing contour must be maintained without appreciable distortion.
efficient column compressive length, internal supporting units are required. These supporting units are referred to as
wing ribs. In the current report, a complete stress analysis subjected to different kinds of loading for a wing rib is
introduced.
The shape of the wing is maintained by wing rib, and it also supports the bending and compressive loads which
act on the wing. The objective was to reduce the weight of the rib and increase the critical buckling strength. Linear static
the detail design of a wing rib under different loading conditions is subjected to buckling, it is found to be safe. Finally,
we concluded that initially the design is of 4.592 Kg \& optimize up to 2.964 Kg, so that weight is reduce by 1.628 Kg
KEYWORDS: Wing RIB, Current Report \& Plate RIB using FEM Packages

Received: Jan 23, 2018; Accepted: Feb 13, 2018; Published: Mar 13, 2018; Paper Id.: IJMPERDAPR201877

\section{INTRODUCTION}

\section{Wing Structures}

The wing consists of spars, ribs, skin, and stringers. The ribs carry chord wise pressure and spars carry shear distributions from the wing skin. The ribs help the wing to keep its airfoil shape, and it resist wing twisting or torsion with the help of the skin and spars form tubes and boxes. From the wing skin, the pressure and shear distributions are transferred to the ribs and distributed to the spars. It also gives aerodynamic shape and transfer load to spars
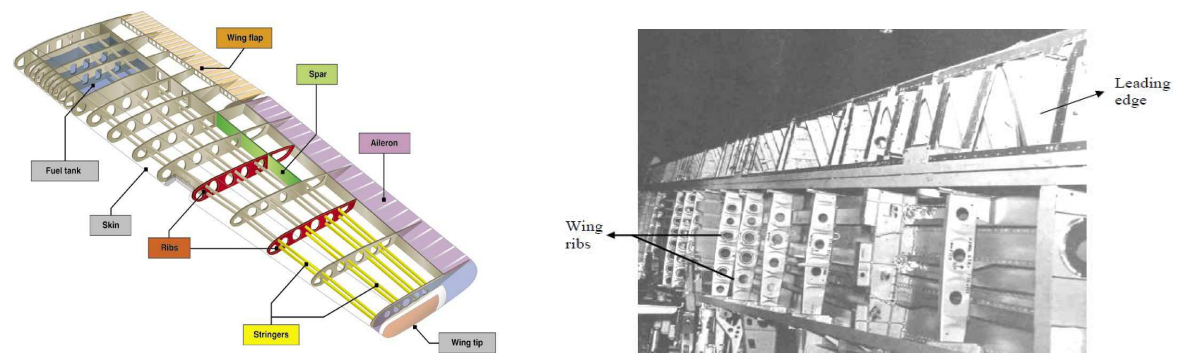

Figure 1: Aircraft Wing Showing the Wing Ribs

\section{Function of Ribs}

Aerodynamic loads through skin-stringer panels are transferred to the rib webs, which in turn transferred to the spars by its roll. Generally, two types of Ribs are presented for aircraft wing structure 
Light Ribs: Limiting the length of stringers to an efficient column compressive strength, which increases the skin-stringers stability under compressive loads?

Heavy Ribs: This ribs transfers concentrated forces resulting from landing gears and power plants support points, to the wing cellular units in the form of distributed shear flows

The rib resists the following loads and force inputs

- In-plane shear

- $\quad$ Rib crushing (brazier load due to wing bending

- Bending load due to the Poisson's ratio effect in wing covers

\section{In-Plane Shear Loading}

A rib provides a stiff shear connection between spars and skins. A rib collects the loads from the skins and the vertical shear load differences between the spars. The torsion loading about the wing box structural axis is reacted by skins and spars as a constant shear flow. The shear flow from the skins is transferred to the rib main body (shear panels). The main body of the rib, the shear panel, carries the shear loads through the rib. At high levels of shear loads the panel may buckle to form diagonal tension fields.
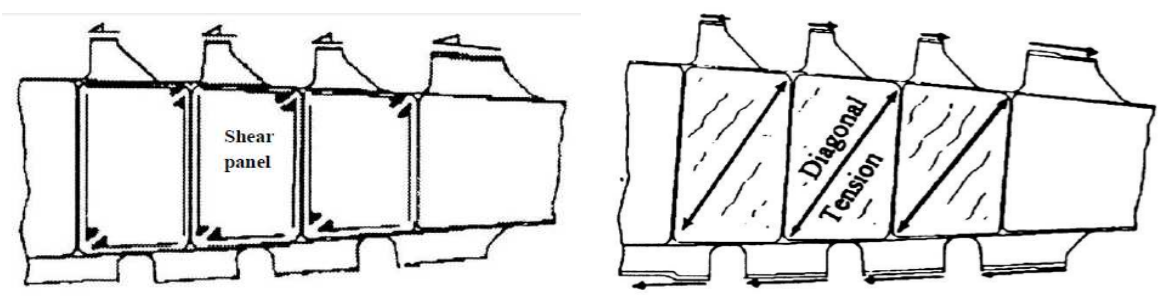

Figure 2: Rib Shear Panels in Higher Levels of Shear

\section{Rib Crushing}

Rib crushing is generated by flexural wing bending-when a wing box is subjected to bending loads, the compression and tension in curved wing skins generates inward acting loads on the wing ribs. This effect is shown in following figure 1.6. The compression in the ribs is reacted by vertical stiffeners or shear panel; in case the ribs do not have any vertical stiffeners or when geometrical stiffening is used. The figure 1.7 shows compression in the rib. Compression is mainly transferred via skin stringers and in an ideal design situation in the rib viewpoint; the vertical stiffeners are vertically aligned with a pair of stringers on upper and lower skins.

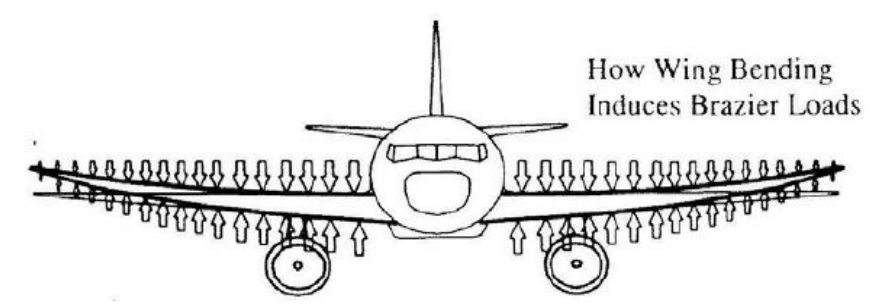

Figure 3: Wing Rib Crushing Load 


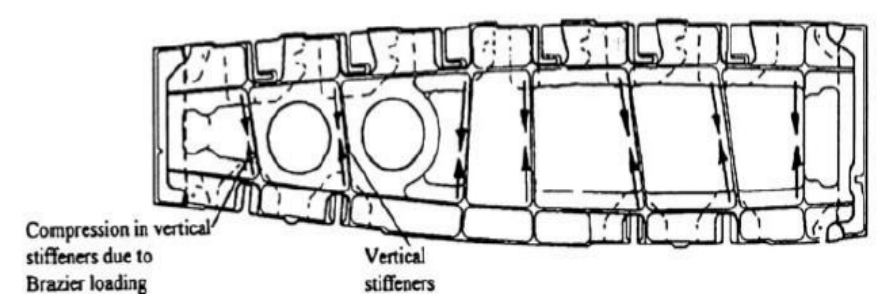

Figure 4: Brazier Load Impact on Rib

\section{Bending Load}

Chord wise bending loads are generated by stresses in the wing skins. In the normal flight, wing bends upward creating a span wise compression in the upper skin and tension in the lower skin. Due to the materials Poisson's ratio, wing skins under stresses generate a bending load to the ribs. Upper cover generates outward tension in the ribs' upper flange, and lower cover generates inward compression in the rib lower flange, this combined load condition tends to bend the rib that is shown in figure 1.8 .

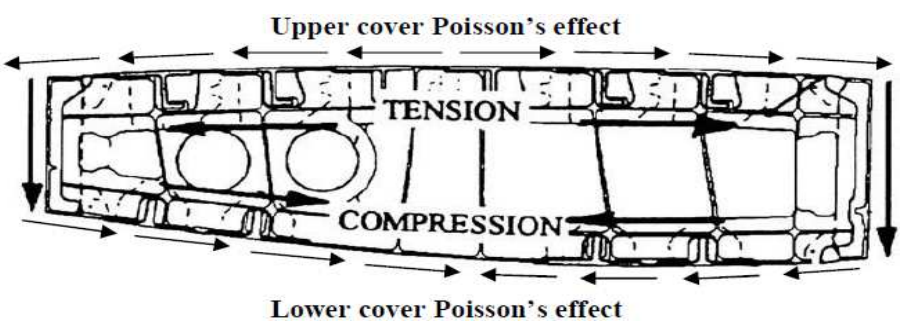

Figure 5: Rib Bending Due to Spar End Loads and Poisson's Ratio Effect in Skins

\section{LITERATURE SURVEY}

Literature papers were collected and presented in the following sections. The literature topics are more relevant to the Rib design and analysis, as a part of aircraft design and development. Three different papers listed below are described in the next following section.

D. Murali Krishna ${ }^{[1]}$ have analyzed the Inter spar ribs of wings of transport aircraft to various types of loads. FEM analysis of inter spar ribs of a wing at local level against brazier load is described. This reduces the weight penalty to the maximum possible extent, wherever feasible. The linear buckling analysis of ribs against brazier load is important analysis of this paper.

Juha Halme ${ }^{[2]}$ proposed thesis to define, design and execute a testing program for 5 composite wing ribs. As a part of work, the loading of the composite wing is studied. The wing ribs are finally manufactured by Resin Transfer Moulding (RTM) manufacturing method. In the material screening part, manufacturing and mechanical performance of 7 different thermoset resin and carbon fibre reinforcement material combinations were studied. As a result of material screening program, single material combination was selected as the wing rib material. Fibre compaction tests were conducted in order to assess the mould closing forces in the RTM process. The driving factors to this thesis is to lower the manufacturing costs, as well as lowering the structural weight was considered to be met by choosing RTM as a method of manufacture. RTM is not a single manufacturing process that can be dealt with in a monolithic manner. 


\section{PROBLEM DEFINITION}

\section{Objectives of the Present Study}

- To fabricate the Carbon Fiber Reinforced plastic wing rib.

- Buckling analysis using FEA in ANSYS.

- Validating results with experimental results.

The present study is focused on the analysis of CFRP wing trailing edge rib, to test its stability under brazier load. The analysis is carried out by FEM methods to study its behavior under the applied load. The basic objective of this study is determination of buckling factors from stiffness point of view. Buckling refers to loss of stability of a component and is usually independent of material strength. This loss of stability usually occurs within the elastic range of the material. The load at which buckling occurs depends on the stiffness of a component, not upon the strength of its materials. Buckling failure is primarily characterized by a loss of structural stiffness.

When a long slender member is subjected to compressive force, it moves lateral to the direction of that force, as shown in figure this is called Euler buckling. The force F, necessary to cause such a buckling motion will vary by a factor of four, depending only on how the two ends are restrained. Therefore, buckling studies are much more sensitive to the component restraints than in a normal stress analysis.
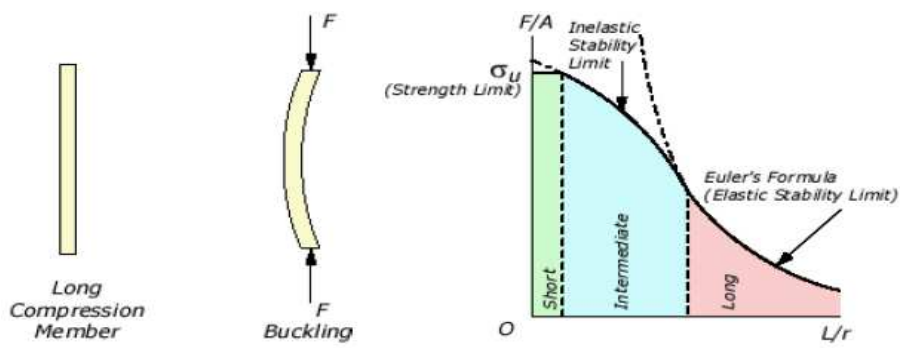

Figure 6: Long Columns Fail Due to Structural Instability

The buckling load factor (BLF) is an indicator of the factor of safety against buckling or the ratio of the buckling loads to the currently applied loads. Analytic buckling studies identify additional classes of instability besides Euler buckling. A finite element buckling study determines the lowest buckling factors and their corresponding displacement modes.

\section{METHODOLOGY}

\section{Material Specification}

Traditional metallic materials used in aircraft structures are Aluminum, Titanium and steel alloys. In the past three decades, applications of advanced fiber composites have rapidly gained momentum. To date, some modern military jet fighters already contain composite materials up to $50 \%$ of their structural weight. Selection of aircraft materials depends on any considerations, which can in general be categorized as cost and structural performance. Cost includes initial material cost, manufacturing cost and maintenance cost. The key material properties that are pertinent to maintenance cost and structural performance are 
- Density (weight)

- $\quad$ Stiffness (young's modulus)

- $\quad$ Strength (ultimate and yield strengths)

- Durability (fatigue)

- Damage tolerance (fracture toughness and crack growth)

- Corrosion

Seldom is a single material able to deliver all desired properties in all components of the aircraft structure. A combination of various materials is often necessary.

The material considered for trailing edge wing rib is Carbon fiber reinforcement plastic (CFRP) with following material properties

- Young's Modulus, $\mathrm{E}=20500 \mathrm{~kg} / \mathrm{mm}^{2}$

- $\quad$ Poison's Ratio, $\mu=0.3$

- $\quad$ Ultimate Tensile Strength, $\sigma_{\mathrm{u}}=91.7 \mathrm{~kg} / \mathrm{mm}^{2}$

- $\quad$ Yield Stress, $\sigma_{\mathrm{y}}=75.8 \mathrm{~kg} / \mathrm{mm}^{2}$

\section{Fabrication}

As a part of work, the loading of the composite wing is studied. The wing ribs are finally manufactured by Resin Transfer Moulding (RTM) manufacturing method. In the material screening part, manufacturing and mechanical performance of 7 different thermo set resin and carbon fibre reinforcement material combinations were studied. As a result of material screening program, single material combination was selected as the wing rib material. Fibre compaction tests were conducted in order to assess the mould closing forces in the RTM process. The driving factors to this thesis is to lower the manufacturing costs, as well as lowering the structural weight was considered to be met by choosing RTM as a method of manufacture. RTM is not a single manufacturing process that can be dealt with in a monolithic manner. Most of the RTM processes comprise out of the following illustrate steps shown in figure
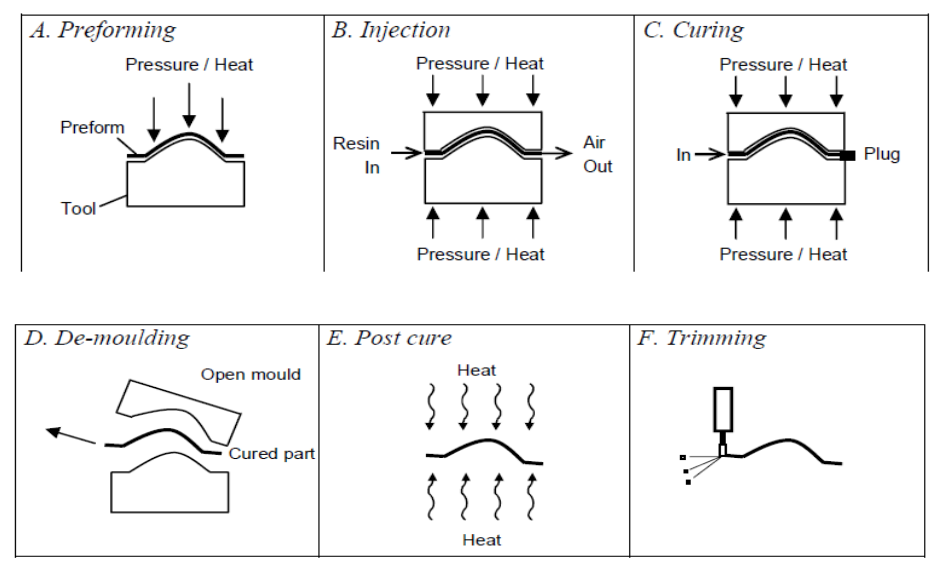

Figure 7: Sequence of RTM 


\section{Finite Element Analysis}

The software used for the analysis of the trailing edge Rib is ANSYS. The stages involved in FEM are shown in the figure

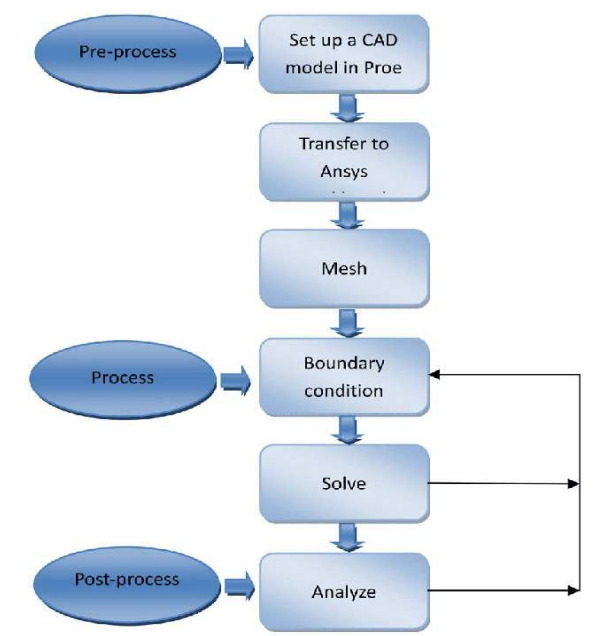

Figure 8: Sequence of ANSYS Procedure

\section{EXPERIMENTAL SETUP}

A structural testing was carried out to find out the critical load for CFRP ribs. As the rib contour is curvature and to apply the load uniformly, two wooden pieces are cut inside into the same curvature, as the rib and load is applied through wooden pieces onto the rib. The experimental set up is as shown in the figure 7.1

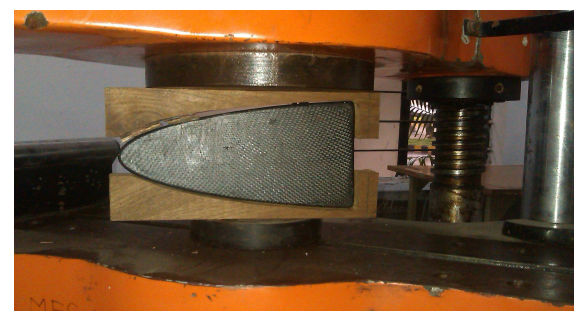

Figure 9: Experimental Setup of CFRP Rib for Buckling Analysis

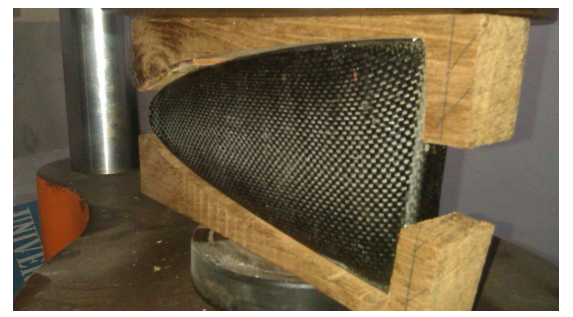

Figure 10: CFRP Rib after Buckling

The critical load for CFRP is found to be 5.6KN.

\section{RESULTS}

\section{STATIC ANALYSIS RESULTS FOR CFRP}

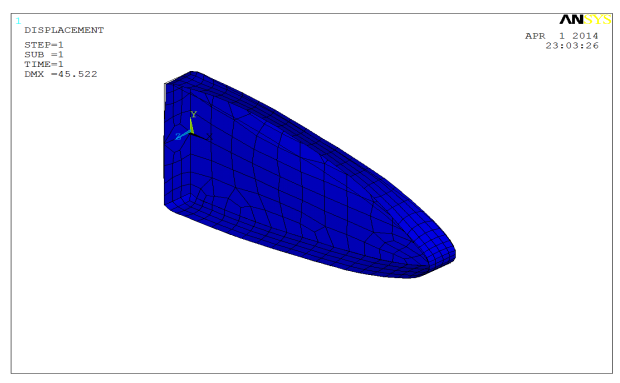

Figure 11: Deformed Shape of Rib

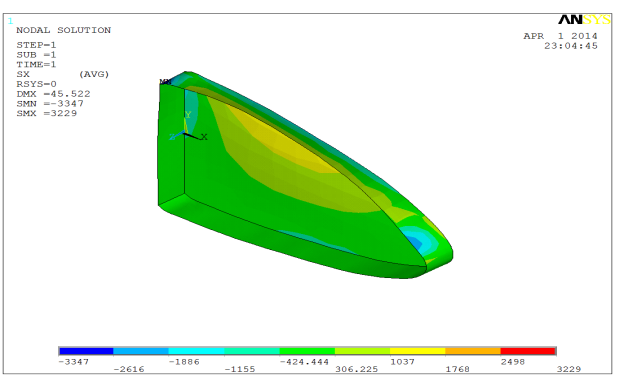

Figure 12: X-Component Stresses Contour 


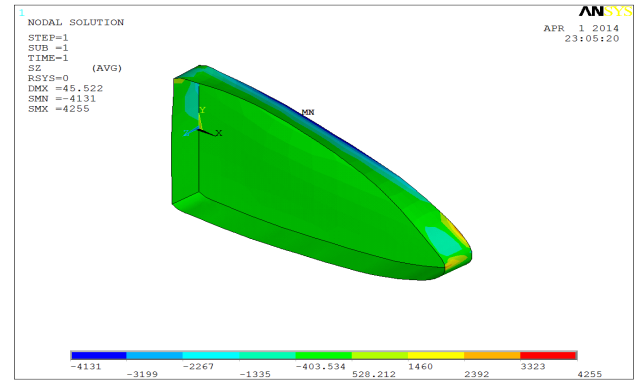

Figure 13: Z-Component Stress Contour

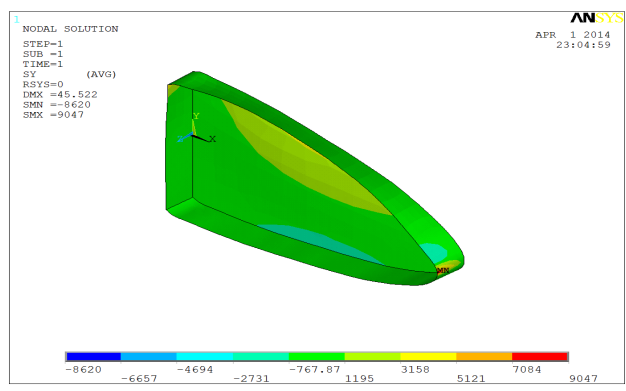

Figure 14: Y-Component Stresses

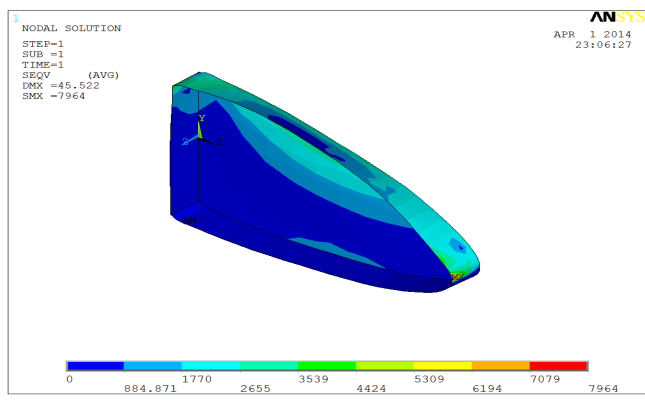

Figure 15: Von Mises Stresses

\section{STRESSES FOR CFRP RIBS}

Table 1: Comparing Maximum and Minimum Stress Values of CFRP

\begin{tabular}{|c|c|c|c|c|c|c|c|c|}
\hline \multirow[t]{2}{*}{$\begin{array}{c}\text { TYPE OF } \\
\text { MATERIAL }\end{array}$} & \multirow[t]{2}{*}{$\begin{array}{l}\text { DEFORMATION } \\
\text { IN mm }\end{array}$} & \multicolumn{2}{|c|}{$\begin{array}{c}\text { X-COMPONENT } \\
\text { STRESSES in } \\
\mathrm{N} / \mathrm{mm}^{2}\end{array}$} & \multicolumn{2}{|c|}{$\begin{array}{c}\text { Y-COMPONENT } \\
\text { STRESSES in } \\
\mathrm{N} / \mathrm{mm}^{2}\end{array}$} & \multicolumn{2}{|c|}{$\begin{array}{c}\text { Z-COMPONENT } \\
\text { STRESSES in } \\
\text { N/mm } \\
\end{array}$} & \multirow{2}{*}{\begin{tabular}{|c|} 
VONMISES \\
STRESSES \\
in N/mm \\
Maximum \\
\end{tabular}} \\
\hline & & Maximum & Minimum & Maximum & Minimum & Maximum & Minimum & \\
\hline CFRP & 4 & 3229 & -3347 & 9047 & -8620 & 4255 & -4131 & 7964 \\
\hline
\end{tabular}

\section{BUCKLING ANALYSIS RESULTS FOR CFRP}

\section{LOAD SUBSTEP 1}

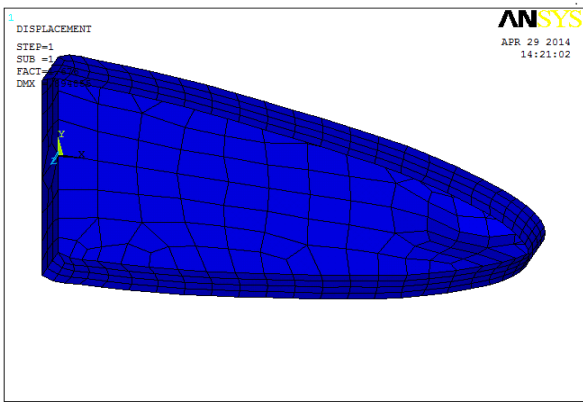

Figure 16: Deformed Shape of Rib for Sub Step 1

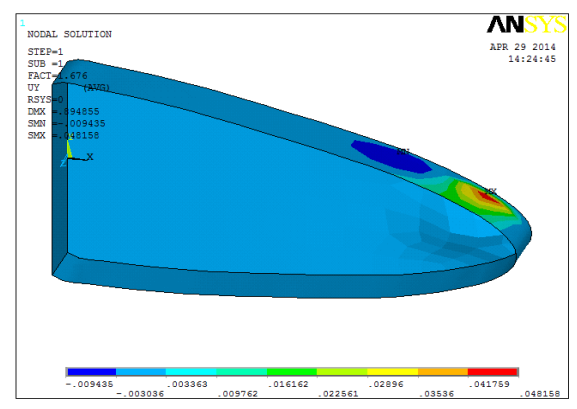

Figure 17: Y-Displacement Contour for Sub Step 1 


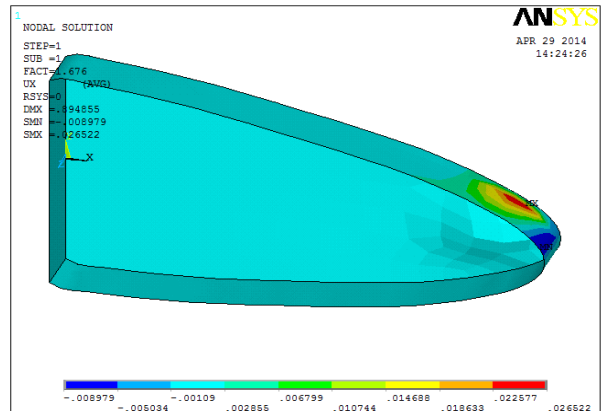

Figure 18: $X$-Displacement Contour for Sub Step 1

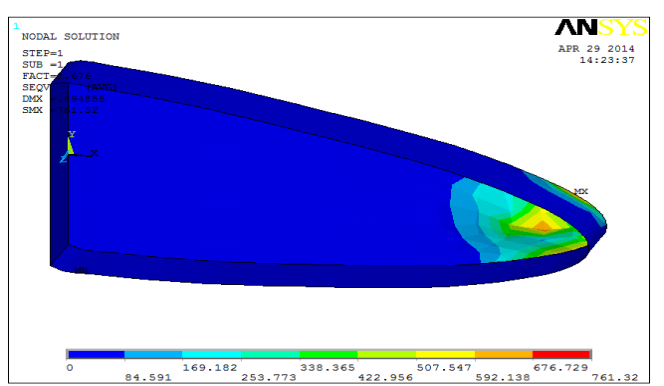

Figure 20: Von Mises Stresses for Sub Step 1

\section{LOAD SUBSTEP 2}

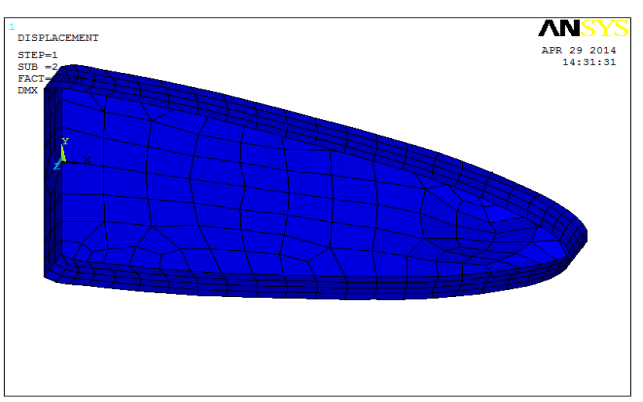

Figure 21: Deformed Shape of Rib for Sub Step 2

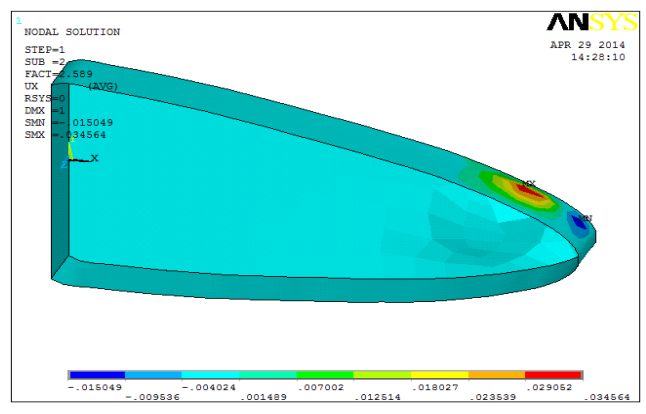

Figure 23: X-Displacement Contour for Sub Step 2

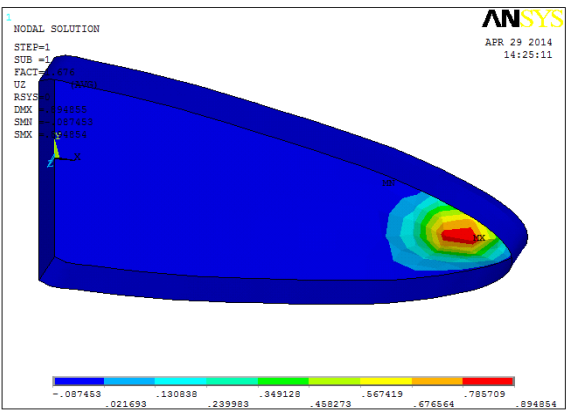

Figure 19: Z-Displacement Contour for Sub Step 1 


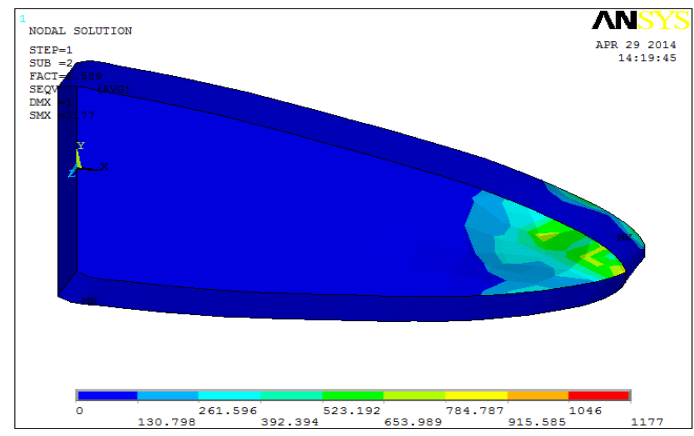

Figure 25: Von Mises Stresses for Sub Step 2

\section{LOAD SUB STEP 3}

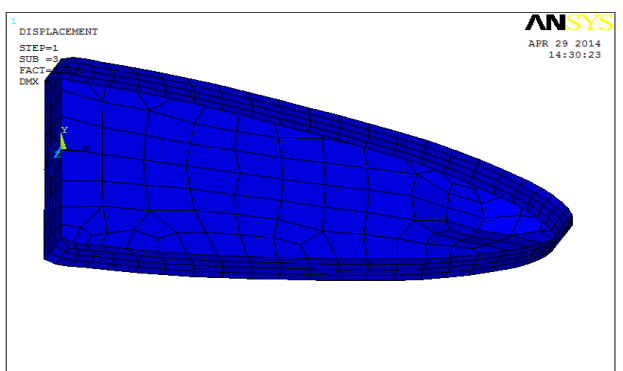

Figure 26: Deformed Shape of Rib for Sub Step 3

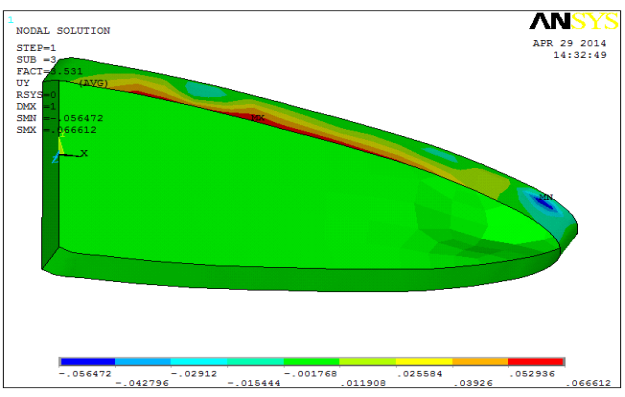

Figure 28: Y-Displacement Contour for Sub Step 3

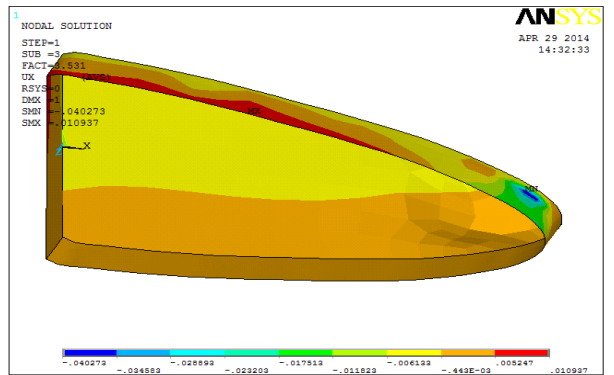

Figure 27: X-Displacement Contour for Sub Step 3

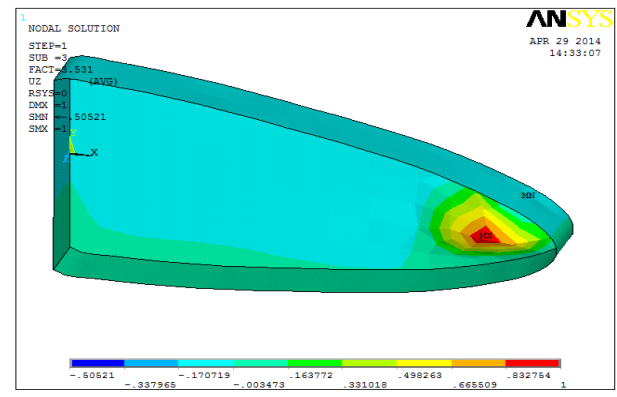

Fig 29 Z-Displacement Contour for Sub Step 3

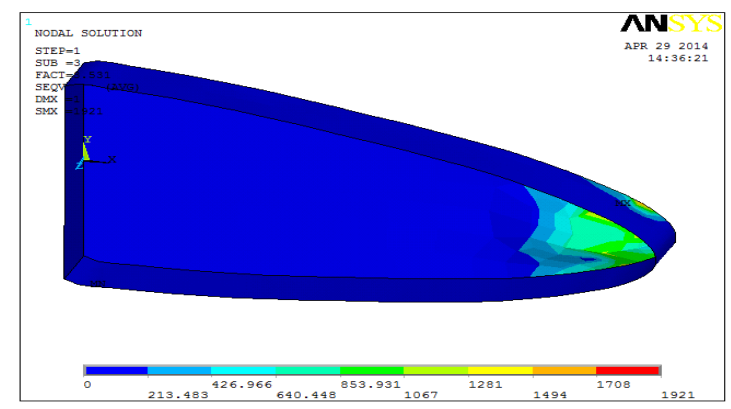

Figure 30: Von Mises Stresses for Sub Step 3 
Table 2: Buckling Analysis Mode vs Frequency Response

\begin{tabular}{|l|l|l|l|l|l|l|l|l|l|l|}
\hline SET & $\mathbf{1}$ & $\mathbf{2}$ & $\mathbf{3}$ & $\mathbf{4}$ & $\mathbf{5}$ & $\mathbf{6}$ & $\mathbf{7}$ & $\mathbf{8}$ & $\mathbf{9}$ & $\mathbf{1 0}$ \\
\hline TIME/FREQ & 1.6758 & 2.5890 & 3.5309 & 3.5383 & 3.7653 & 4.1906 & 5.2353 & 5.9238 & 5.9765 & 6.4049 \\
\hline
\end{tabular}

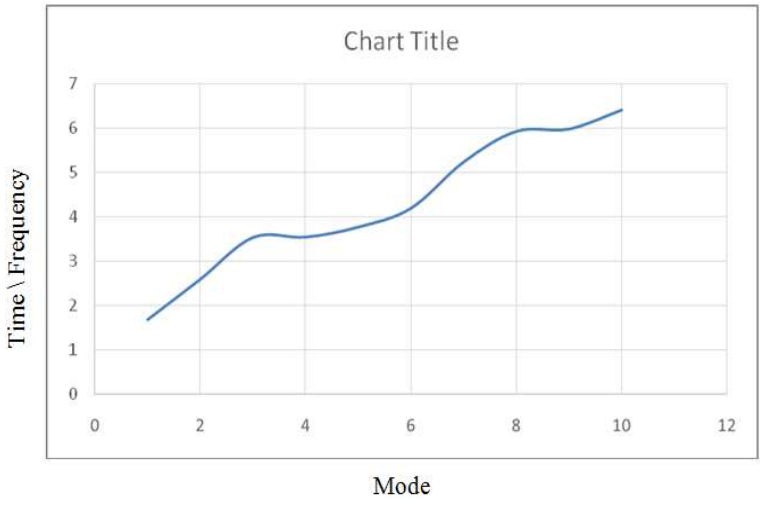

Figure 31: Mode vs Time/Frequency for Different Load Steps

\section{CONCLUSIONS}

- Stress analysis of the CFRP rib is carried out and maximum tensile stress is identified.

- Buckling analysis is carried out for CFRP trailing edge rib and critical stresses are found out.

- FEM approach is followed for the stress analysis of the wing trailing edge rib.

- Maximum compressive stress for CFRP is $9.47 \mathrm{KN} / \mathrm{mm}^{2}$ is observed in the CFRP rib

- Experimental buckling analysis is carried out and critical load is found out.

- The critical buckling loads are found to be 5.6KN for CFRP.

- Since stresses are developed for CFRP rib, critical load is higher for CFRP than other materials and have good compressive strength

\section{REFERENCES}

1. FEM analysis of Inter spar ribs of composite wing of light transport aircraft against brazier load, Polagangu James, D.Murali Krishna, Gaddikeri Kotresh and Byji Varughese. Advanced Composites Division, National Aerospace Labaratories, Bangalore.

2. Development Testing of a Composite Wing Rib, Juha Halme. Helsinki University of Technology, Department of Mechanical Engineering.

3. Wing-Box Structural Design Optimization, Ramin Sedaghati, Mostafa S.A. Elsayed. Department of Mechanical and Industrial Engineering Concordia University

4. Finite element mesh refinement criteria for stress analysis. References and further reading may be available for this article. To view references and further reading you must purchase this article. Madan G. Kittur and Ronald L. Huston, Aero Structures, Inc., 1725 Jefferson Davis Highway, Suite 704, Arlington, VA 22202, U.S.A., Department of Mechanical and Industrial Engineering, University of Cincinnati, Cincinnati, OH 45221-0072, U.S.A.

5. Sechier (E.E.) and Dunn (L.G.), "Airplane Structural Analysis and Design", Dover Publications Inc, New York, 1963. 
6. Cecchini, Luca S. and Weaver, Paul M., "The Brazier Effect in Multi-bay Aerofoil Sections", Palm Springs, California, AIAA 2004-1522, 45th AIAA/ASME/ASCE/AHS/ASC Structures, Structural Dynamics \& Materials Confer 19-22 April 2004.

7. Krong, Lars; Tucker, Alastair and Rollema, Gerrit, “Application of Topology Sizing and Shape Optimization Methods to Optimal Design of Aircraft Components," Advanced Numerical Simulations Department, Airbus UK Ltd, Bristol, Altair Engineering Ltd., 2002.

8. Buchanan, Sid, "Development of a Win box Rib for a Passenger Jet Aircraft using Design Optimization and Constrained to Traditional Design and Manufacture Requirements,” Bombardier Aerospace, Belfast, Northern Ireland, Altair Engineering Ltd, 2007.

9. Bulson, P.S., “The Stability of Flat Plates,” Published by Chatto \& Windus Ltd., 1970.

10. S. Lokesh et al.,;, Buckling Analysis of Laminated Composite Plates using Layer Wise Higher Order Shear Deformation Theory, International Journal of Mechanical and Production Engineering Research and Development (IJMPERD), Volume 7 , Issue 5, September - October 2017, pp. 63-74

11. Krishna, D. Murali; Varughese, Byji; Venkatesh, S.; Asha, Kumari; Banker, Manisha M. and Rao, M. Subba, “Analysis of Composite Wing for SARAS Aircraft”, PD AC-0715, Advanced Composites Division, NAL, Bangalore, November 2007.

12. Gaddikeri Kotresh, Polagangu James, Byji Varughese, M. Subba Rao, et al., "Design of Composite Wing for SARAS Aircraft", PD-AC-0714, Advanced Composites Division, NAL, Bangalore, November, 2007.

13. Bruhn E.F, Analysis and Design of Flight Vehicle Structures, Jacobs \& Associates Inc., June 1973 Wagner, H., and Ballerstedt, W. "Tension Fields in Originally Curved, This Sheets During Shearing Stresses". NACA TM 774, 1935. 
